\title{
Lesson Learned - The Quality of Life Development and Income Enhancement for The Local Community Project from The Mission as a Higher Education Institute for Local Development of Phranakhon Rajabhat University
}

\author{
${ }^{1}$ Chanthana Udom, ${ }^{2}$ Phairoj Butchiwan, ${ }^{3}$ Nongnooch Paiboonrattananon, ${ }^{4}$ Phrapalad Somchai \\ Damnoen \\ ${ }^{1,2,3}$ Faculty of Management Science, Phranakhon Rajabhat University \\ ${ }^{4}$ Mahachulalongkornrajavidyalaya University \\ ${ }^{1}$ chanpnru@gmail.com, ${ }^{2}$ phairoj@pnru.ac.th, ${ }^{3}$ nong.pong@gamil.com, ${ }^{4}$ somchai.dam@mcu.ac.th
}

\begin{abstract}
This article aims to present the conceptual framework of the project implementation process and its result of the mission as a higher education institute for local development, Phranakhon Rajabhat University. This is a part of the quality of life development and income enhancement for the local community. The target of the project was farmers and small and micro-community enterprises (SMCE) in Bang Yai district, Nonthaburi, covering 4 sub-districts with 60 households. The methodology focused on building partnership networks and defining the common goals by analysis of the capital and capacity, in which involving problem-solving. Additionally, it also emphasized on finding solutions that leading to academic development via participatory process. This was to solve problems and support the ongoing implementation of the local community. The tools used in the project were group discussions, in-depth interviews, and workshops. The results of the project implementation were a plan for problem-solving and development projects of the local community. They consist of 1 megaproject and 10 sub-projects with substantial results. It also has to be consistent with the needs of the users and be applicable for further development in income enhancement for farmers in the future
\end{abstract}

Keywords

Local Development; Local Economy; Phranakhon Rajabhat University

Article Received: 10 August 2020, Revised: 25 October 2020, Accepted: 18 November 2020

\section{Introduction}

Phranakhon Rajabhat University has settled a new strategy called Phranakhon Rajabhat University for Local Development under the Royal Command for 20 years (2017 - 2036). This has been done by applying His Majesty King Rama 10's speech which is 'the problems and the needs of the local community must be acknowledged and analyzed to initiate new strategies for developing and adjusting to the local customs accordingly'. The driven strategy is designed into four areas; local development; producing and developing instructors; enhancing the quality of education; the development of the management system and connecting the concept of the engagement university and society. The objectives are to focusing on the development and support of suitable innovation, knowledge, and technology for the local area, as well as a learning process for enhancing and elevating cooperation networks according to the context of each university, faculty, or department[1]. For this, the integrated management principles have been applied to improve the area through the cooperation of the university and partnership networks towards goals and visions for joint development at the sub-districts, provinces, and country. Hence, to achieve these goals, the mission including research, teaching, academic services are integrated while fostering of art and culture with the actual situations in the local community. Besides, roles and processes of teaching are also accommodated to meet the need of society [2] by considering the benefits that the learners would practically apply into their lives and use them for further development of the country[3].

Phranakhon Rajabhat University has adopted the Educational Royal Policy of being an educational institute for local development by implementing the 20-year local development strategy of Rajabhat University (2017 - 2036). There are 4 areas of responsibility consisting of Northern Bangkok, Nonthaburi province, Chai Badan Phiphat College in Lopburi province and Nakhon Nayok province, to drive the strategy of Rajabhat University for local development based on mutual knowledge and understanding [4]. Since Phranakhon Rajabhat University is a higher education institute which is a source of knowledge and experiences of researchers and scholars with expertise in various disciplines, we, thus, can integrally coordinate to achieve the connecting system. This is to improve and strengthen entrepreneurship, as well as to create awareness of environmental protection and various facilities based on the needs of the community. Also, it is to establish a direction of development in a continuous process and to build an integrated work with all sectors for encouraging the local community to cope with changes and to be sustainably selfsufficient.

For the implementation of the quality of life development and income enhancement for the local community project, the team had determined the target area to be Bang Yai district. The problem condition was discussed and analyzed via two joint meetings between instructors of the General Management Program, Faculty of Management Science, and the sheriff of Bang Yai district. The sheriff described the 
situation and the context of the development direction of the Bang Yai administrative region, which is one of the districts in Nonthaburi province with a large population which has gained rapid prosperity. In the past, most of the area was agricultural land (in 2009, a total of 29,215 rai was agricultural area). However, as the boom from Bangkok has continuously expanded to Bang Yai and Bang Bua Thong, more than 200 housing estates were built. Private companies and several government agencies also moved to the area, causing the land price to be significantly skyrocketing. The economic growth is the main factor of the expansion of urbanization by scattering invading into natural and agricultural areas. This has caused permanent loss of fertile lands, which are lands of food production and water reservoirs. Therefore, Bang Yai presently has only 19,000 rai of agricultural land remaining.

From the issue above, the governmental chief in charge of Bang Yai region development has reviewed and formulated plans to encourage the protection, conservation and preservation of the remaining farmland. The area has been preserved to be a source of quality and safe food for people while maintaining the green space for the city. The ways for halting urban sprawl have been concisely planned and properly managed to create an environmentally friendly city with a balance between urban development and sustainable resources [5]. Moreover, the solution to stop the further invasion into the remaining farmlands has been constructed by changing attitudes of farmers by guiding them to realise the importance of their farms as quality food sources for societies. This is significantly relevant to all elements of urban development in physical, economics, income, health, environment, and property management, which enable to enhance their income appropriately.

The research concerning of the current situation in Bang Yai district and the sheriff's interviews suggested the proposal to strengthen the economy, promote local wisdom, generate income, support each other and improve management capability for encouraging farmers to be self-reliant and developing a strong economy in the community. The goal is to raise the quality of life of farmers for achieving sustainable development under the Sufficiency Economy Philosophy. The strengthening of community agriculture and society as a foundation for building the potential food security in the area has been prepared by balancing between the production process on a potential basis and the tenacity of the community. To prioritize to the stability of the community economy, the production has been focused on sufficient consumption within the district and developing a system for community agricultural enterprises in parallel with creating new entrepreneurs. In order to achieve this, knowledge of management and marketing by implementing digital commerce has been utilized.

Therefore, the General Management Program, Phranakhon Rajabhat University has proposed 'the Quality of Life Development and Income Enhancement for The Local Community Project' to commercially benefit the development of farmer community, which expectedly lead to building on the new generation of entrepreneurs. This aims to be the major motive in supporting knowledge in management, production skill, distribution channels, the development of digital commerce. The other goal is to create awareness of community farmers to realize the importance of their assets as a quality source of food production for local society. Moreover, they are the key figures in preventing urban sprawl that invades the remaining agricultural areas of Bang Yai district to preserve quality food source and conserve the green space of the society. This would not only increase economic growth at the community level but also sustain their environment.

\section{Research Objective}

To present the conceptual framework, operation process, and the results of 'the Quality of Life Development and Income Enhancement for The Local Community Project'

\section{Research Scope}

Scope of contents: study the concept of Sufficiency Economy Philosophy, local economy development, goals of sustainable development, methodologies and activities for developing the quality of life and enhancing income for local community, building a working network for improving the quality of life in the community, and effective management

Area of population: the target groups for this project are 60 households of community farmers and community enterprises in Bang Yai district, Nonthaburi province. Duration: December 2019 - August 2020

\section{Literature Review And Conceptual Framework}

In 2019, member states of the United Nations (UN) adopted the Sustainable Development Goals (SDGs) to be achieved by 2030 . The SDGs is a collection of 17 interlinked global goals with 169 targets covering three critical issues of sustainable development; the economic, social and environment. The ultimate goals are ending poverty, reducing disparity by Leave No One Behind, combating climate change, and encouraging the participation of all countries, all stakeholders, and all people to driving sustainable development. The SDGs addresses the significant balance in three dimensions. Thailand has had its development framework for achieving sustainable development, which is the Sufficiency Economy Philosophy. It is based on intellect, virtue, the middle line of life, rationale and providence according to the concept of King Bhumibol Adulyadej. Similar to the SDGs, the main focus of the Sufficiency Economy Philosophy is sustainability.

Universal Development is a development process that every country must achieve together. Even developed countries such as countries in Scandinavia still have faced challenges in some issues. As suggested by data from SDG index 2016, these countries show a relatively good level in the economic and social aspects. However, the environmental issue, especially in Goal 12; Responsible Consumption and Production, remains challenging. In addition, all countries will be globally affected by climate change, the most problematic environmental issue of humanity. Cooperation is hence inevitable. Locally-focused development means that to achieve the SDGs, the development has to be done at 
the local level like rural areas or cities. This is because each area has distinct conditions, contexts, capital, needs and challenges. The local development by encouraging and empowering stakeholders to take leading roles is therefore critical to accomplish the SDGs. This is to realise the problems and find solutions which are corresponding to each area by considering the SDGs as the target and the indicator for interlinking experiences of each area [6].

\section{A. The twelfth national economic and social development plan (2017-2021)}

As of lately, Thai society has progressed in many ways. However, the attempt to solve social disparity and justice have been relatively slow, especially in the income inequality issue. Therefore, the development for the coming phase needs to focus on reducing the income inequality between people with different socioeconomic status. The plan also has to tackle poverty and increase the accessibility to basic welfares from the public sectors. Moreover, the community capacity and local economy have to be strengthened for gaining more economic share and being self-reliant. The important approach is to increase the opportunity to $40 \%$ of the population with the lowest income to have career and access to quality welfares. The community capacity, local economy, and microfinance can be reinforced according to The Sufficiency Economy Philosophy. It will allow people to have rights in land and resource management in their community. Thus, the significant development for this coming five years is to advance competitive capacity for production and service. The improvement needs to emphasize value chain connection among agriculture, industry, service, trading, and investment. The competitive capability of the country must be elevated by upraising agricultural and food production to the standards.

\section{B.The Development of Local Economy}

The development of the local economy is one of the significant goals under government policy. Inequality issue in Thailand is a consequence of the past development plans on several issues such as income, educational opportunity, employment, occupational security, accommodation, the use of land, public health, drugs, life and property safety, and family [7]. The building of a potential community economy by reducing disparity, developing human capability, and increasing competitiveness of the country, will lead to income and happiness enhancement [8]. The community will then become economically self-reliant and sustainable, especially in development that benefits numbers of people in the community. Community economic development is a holistic viewpoint of economic strength factor, which means it is an economic measurement to all community capitals [9]. Community capitals consist of; 1) Financial capital such as Saving for Production Group (SPG), poverty reduction fund, and village and urban community fund; 2) Natural capital such as soil and water fertility and natural tourist attractions; 3) Social capital, for example, communities and organizations, skill and proficiency in production and management, et al. for strengthening community sustainability [10].
The literature review above has led to the conceptual framework of the project with the ultimate goal to create a driven mechanism to achieve the SDGs, local economic development, and strategies of Phranakhon Rajabhat University. The project management is defined by focusing on a building and developing an integrated network for local development[11]. The integrated network in the implementation consists of the sheriff Bang Yai district, the chief of Bang Yai District Agricultural Extension Office, community leader, private sectors and the National Bureau of Agricultural Commodity and Food Standards (ACFS). The team is responsible for designing activities, determining and developing cooperation in management network, supervising and monitoring the responded area to be effective (by improving the quality of life and enhancing income in the local community) [12]. The activities comprise of; action leading to problem resolution and action for the development in the target group. The implementation of this project has three expectations for improving the quality of life and enhancing the income for the local community; 1) Forming partnership networks from multiple sectors; 2) Collecting body of knowledge as a community capital; 3) Developing supportive tools for income enhancement for the local community. The conceptual framework can be summarized

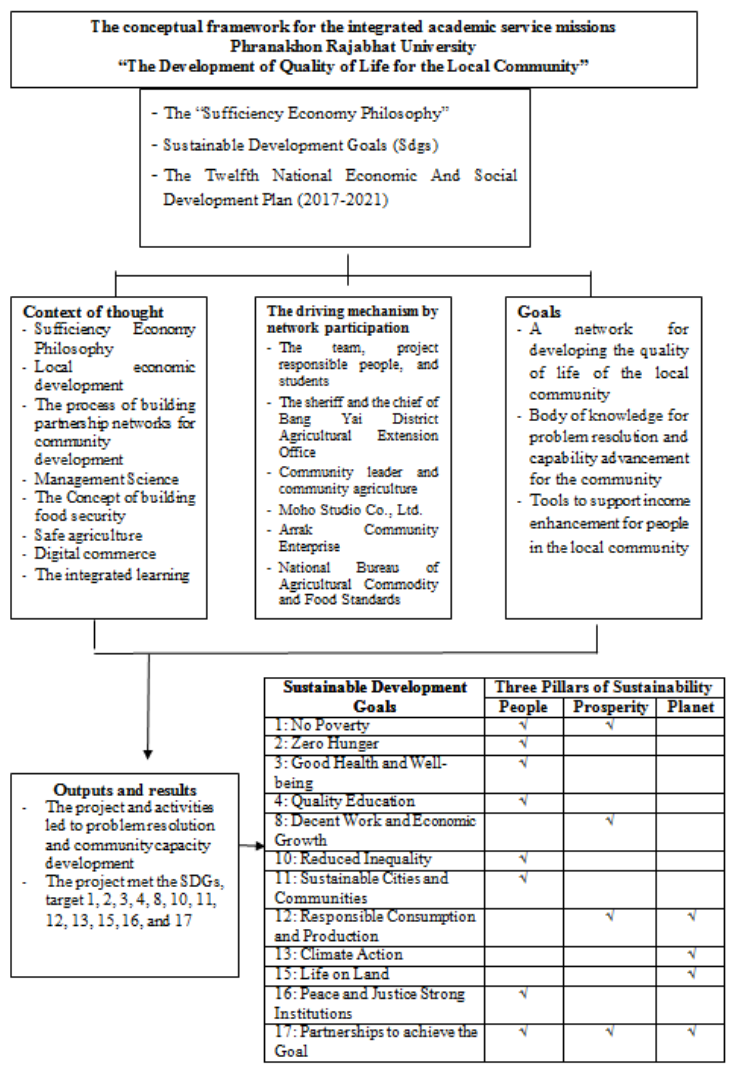

Fig.1 The conceptual framework

\section{C.Implementation methodology}

The project team designed the implementation process as follows;

1)Develop the project proposal - problems and needs for development were researched by meeting and interviewing the sheriff to discuss contexts, conditions, issues, and 
demands for the local development; The local facilities and agencies were also introduced for effectively supporting the project.

2)Determine and develop the cooperation of the partnership networks for implementing - the responsible team synthesized two activities for the community; 1) activity for problem resolution of the community; 2) activity for further development in the target group. These would indicate the particular knowledge required for the implementation, following by finding the relevant agencies with expertise. Then we proceeded to coordinate with partnership networks by informing principles, objectives, process, and the goals. The project received cooperation from 5 agencies. 3)

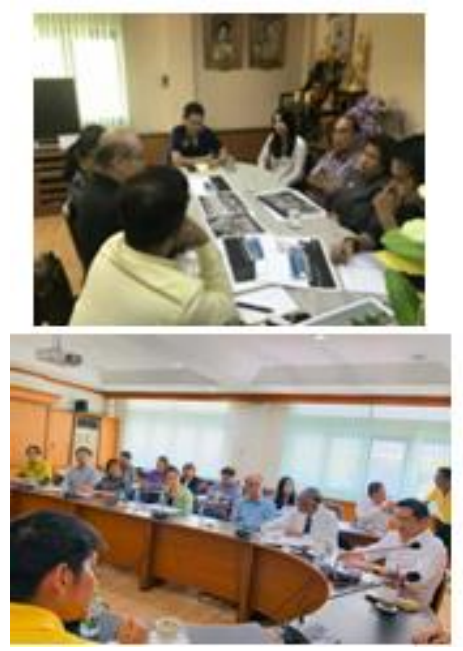

Fig.2 Development of cooperation with partnership networks

4)Integrate the common goals with the partnership networks by participating in the capital and potential analysis - the existing capital of the partnership networks is generally linked to problem solving and approaches for development by academic science. The study was conducted by a participatory process that leads to problem resolution and support to strengthen community implementation. The essential information was from agricultural extension office, which was used as the basis for ten target groups covering four sub-districts. All target groups willingly participated in the implementation.

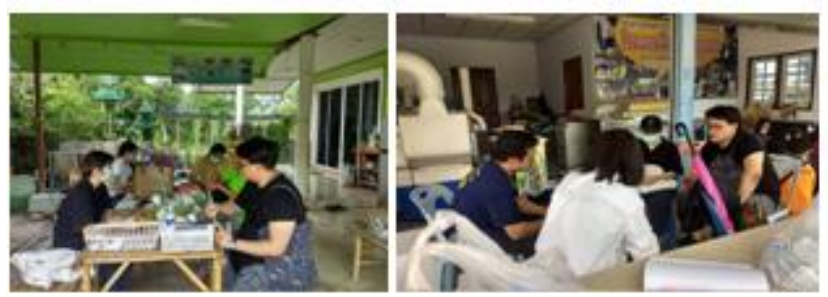

Fig.3Interview with the key informants

5)Coordinate with Bang Yai district agricultural extension office for fieldwork appointment - the instructors, students and the partnership networks then visited the community for conducting inquiries, surveying, observing and constructing a workshop. The ideas were shared and analyzed for the feasibility of working with all ten target groups and using them as information for activity design. The issues related to the learning were assigned into four subjects which are human relations in organization, the seminar on management problems, social marketing, and preparation for professional experience general management. Using academic science through a participatory process would lead to problem and need solving of the community. Besides, this method would be integrated with the expertise which is the original capital of the area.
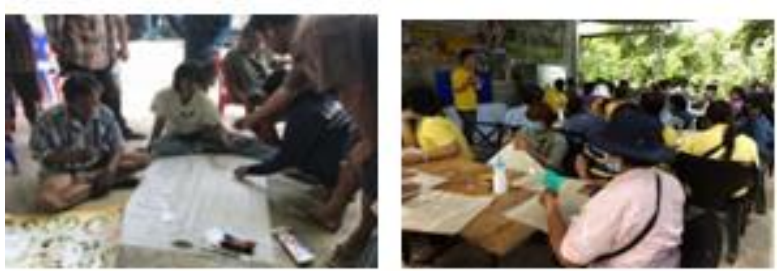

Fig.4 Photos of fieldwork activities

6)Promote the results of the implementation to be concrete the lesson was summarized into the knowledge and innovative arisen from a driven working process with five partnership networks and ten community networks. Then the information and results were given back to the community for productive use. The staffs were the main mechanism to advocate knowledge and integrate the community service project into the learning courses. The area was also set to be the learning workshop between instructors and students. The implementation of the project is concluded in Fig.5

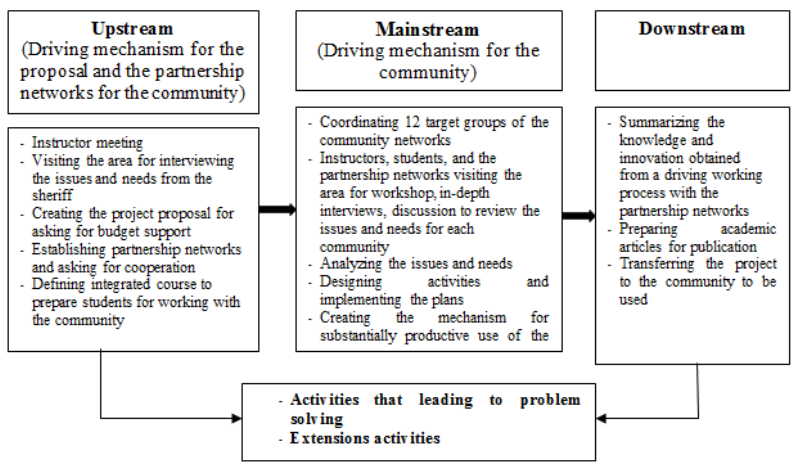

Fig.5 the implementation process of the project

\section{Results}

The project methodology presented above resulted in concrete implementation. The results were analyzed to obtain the knowledge and innovation derived from working with the partnership networks (five agencies and ten community networks). The obtained lesson was transferred to the community to be used as follows;

1.According to the successful project, it was found that the cooperation networks was an important mechanism in the project to enhance the quality of life and income to the community. They consisted of five agencies: Phranakhon Rajabhat University, Bang Yai District Agricultural Office, National Bureau Agricultural Commodity and Food Standards (ACFS), Moho Studio Co., Ltd. and Arrak community enterprise.

2.The implementation results were consistent with the needs of the community. The lesson, therefore, could be practically applied to the area and the learning courses to improve the quality of life and enhance the income of the community. The outcome of the community service project 
was also in agreement with the user demands and led to several project initiations. There are one mega-project and ten sub-projects for problem-solving and community development covering four sub-districts. Sub-projects consist of: 1) Agro-tourism Development Project; 2) Brand Image and Public Relation Channels Development Project for the Community Rice Mills; 3) Channel of Distribution Development Oroject for Bueng Bua Products by Khun Loong Prasit; 4) Public Relations Project for Chemical-free Rice at New Theory Agricultural Learning Centers; 5) Project for Promoting the Local Ggriculture with Environmentally Friendly Consciousness by Young Generation; 6) Project for Development of Online Marketing and Brand Image of Healthy Fruits and Vegetables from Community Farmers; 7) Large Scale of Rice Field Knowledge Embodiment and Dissemination Project; 8) Project for Public Relations Media Creation for Maliwan Farm; 9) Public Relations Media Creation for Four-region Kitchen Project; 10) 'Life Like Rice' Project for Organic Rice.

3.A set of knowledge in a learning process and its design by participation in sustainable local community development prepared students to serve society. The learning process in the King's Philosophy on Sufficiency Economy also shaped students to live their lives properly. It also motivated three attributes of being a student, an innovative contributor and a good citizen as specified in the announcement of the Ministry of Education on National Education Standards 2018.

4.The implementation met twelve direct and indirect goals of the SDGs. It comprehensively covered all social, economic and environmental dimensions including Goal 1: No Poverty; Goal 2: Zero Hunger; Goal 3: Good Health and Well-being; Goal 4: Quality Education; Goal 8: Decent Work and Economic Growth; Goal 10: Reduced Inequality; Goal 11: Sustainable Cities and Communities; Goal 12: Responsible Consumption and Production; Goal 13: Climate Action; Goal 15: Life on Land; Goal 16: Peace and Justice Strong Institutions; Goal 17: Partnerships to achieve the Goal. The project also achieved the goals to develop the local economy and strategies of Phranakhon Rajabhat University.
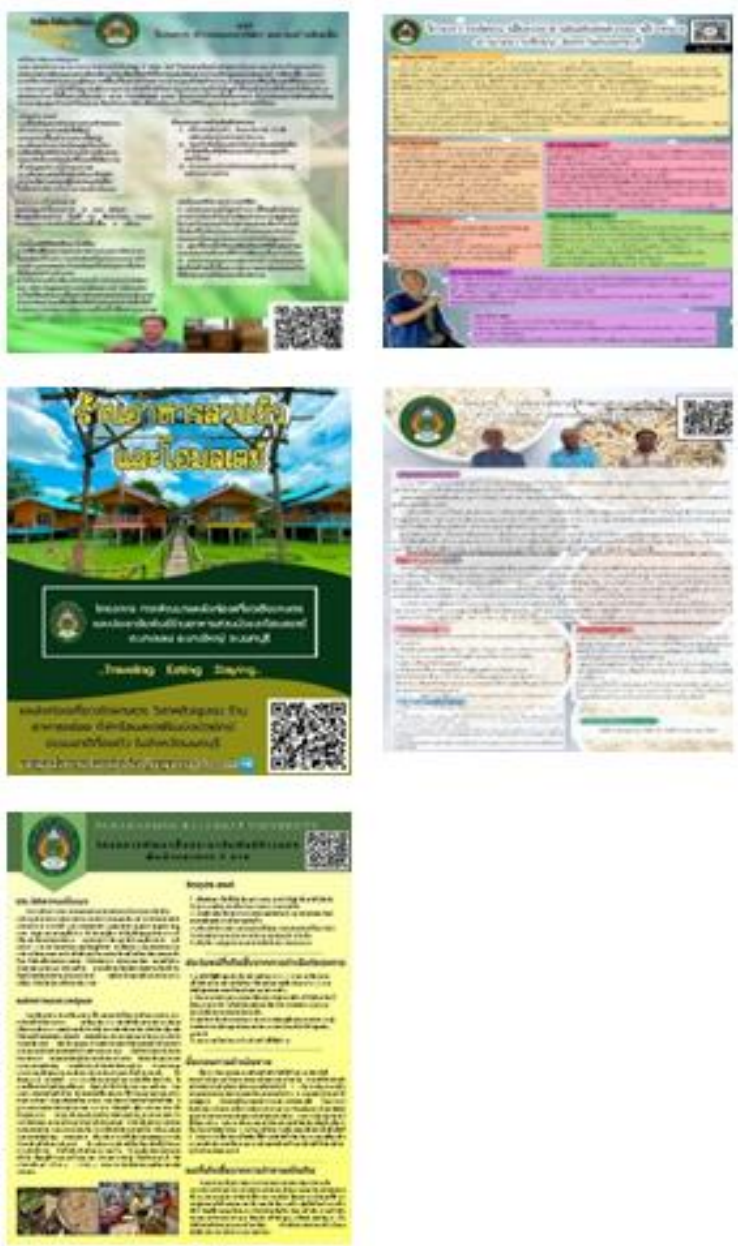

Fig.6. Examples of the implementation results

\section{Conclusion}

Phranakhon Rajabhat University adopted the Educational Royal Policy for being an education institution for local development. We proceeded the implementation by following the 20-year strategies of Rajabhat University for local development $(2017$ - 2036) in all four criteria. The strategies were driven by mutual knowledge and the actual needs of the community. The development was in an integrated work with all sectors in the direction of a continuous process in order to encourage the local communities to be sustainable self-reliant and enable to cope with changes. This article is a lesson learned from the project implementation of the mission on being a higher education institution for local development. The study consists of the conceptual framework, the implementation process, and the results. The team members found six important factors that led the project to success, which are:

1)The explicit conceptual framework enabled the team members to work towards the same goals. This project exploited the Sufficiency Economy Philosophy as a working compass. There were processes of critical thinking, identifying problems, searching resolutions throughout the operation.

2)The personnel in the project are knowledgeable, capable and enthusiastic in their work. They have the responsibility 
and dedication to achieve the goals. They also learned and shared several experiences during the project.

3)The cooperation obtained from the partnership networks with expertise caused interdependence between groups. This also resulted in long-term interaction.

4)Determining the common goals and being open-minded to opinions from the partnership networks enhanced the capability to obtain useful guidelines for the project.

5)Encouragement, empowerment, and listen to the target groups helped the implementation to meet the goals.

6)Effective communication and coordination

\section{Acknowledgement}

We would like to express our sincere gratitude to Phranakhon Rajabhat University for financial support. We are also thankful for the cooperation from five partnership networks, Bang Yai district community network in Nonthaburi province, and all those involved in driving the implementation to be accomplished. Lastly, we hope that this article will benefit the public in applying ideas, perspectives, and others to operate their project to be quickly fruitful in a short period.

\section{References}

[1] Internal Quality Assurance Committee Higher Education, "Guide for Internal Educational Quality Assurance in Higher Education B.E.2557'. Nonthaburi: Pap Prints, 2015.

[2] S. Suwannachat, A. Kooariyakul \& U. Chuaykarn, "Mission Integration: Challenging Roles of Instructors in Higher Education Institutions". The Journal of Baromarajonani College of Nusing, Nakhonratchasima, vol.25 no.1, pp.159$175,2019$.

[3] P.S.P. Damnoen and P. Phumphongkhochasorn, "The Development of the Innovative Model of School Administration in the Secondary Education Area Office 18". Solid State Technology. vol.63 no. 2s, pp.2058-2065, 2020.

[4] Phranakhon Rajabhat University, "Annual performance report 2019 according to the Rajabhat University Strategic Plan for Local Development Fiscal year 2019" . Bangkok: Policy and Planning Division, Thailand, 2019.

[5] A. Jumrusjarongpol and E. Anukulyuthathon, "The Effects of Urban
Development on Conservation of Green Area: A Case Study at Klong Aom, Nonthaburi Province",. NAJUA: History of Architecture and Thai Architecture. Vol. 29, pp.371-385, 2015.

[6] C. Bunnag et al, "Research Coordination for SDGs". Bangkok: Thailand Research Fund, 2018.

[7] Y. Chaiworamankul, P.W.V. Inthapho, P.S.P. Damnoen and P. Chaibuntan, "Integrating Governance for Good Life in the Current Thai Societies". Solid State Technology, vol.63 no.2s, pp.17531761,2020 .

[8] Office of the National Economic and Social Development Board Office of the Prime Minister Bangkok, "The Twelfth National Economic and Social Development Plan (2017-2021)". Bangkok, Thailand. Retrieved from http://www.prachinburi.go.th/plan10.pdf, 2017.

[9] T. Teetakaew, “ Strategies for Development of Community Economy Based on Foundation Economic Culture in Eastern Area of Pathumthani Province". Journal of Srinakharinwirot Research and Development. Vol.4 no.8, pp.39-52, 2010.
[10] Foundation Economic Strategy Subcommittee, "Promoting the development of the foundation economy system". Bangkok: Community Organization Development Institute (Public Organization), 2016.

[11] Department of Provincial Administration, "Community Enterprises: Foundation Economic Mechanism". (6th ed.). Bangkok: Center for Political Economy Studies, 2013. 